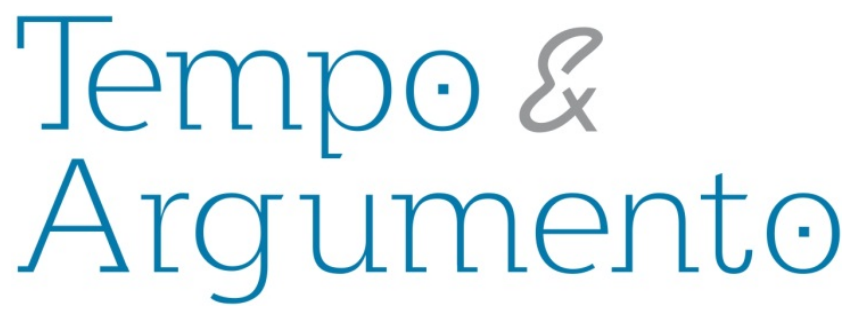

\title{
A cor do abandono: as crianças em situação de rua no Recife na Ditadura Civil-Militar (1964-1985)
}

\section{Resumo}

A historiografia registra que o cenário urbano do Recife, durante a ditadura civil-militar (1964-1985), foi marcado por crescimento econômico e aumento das desigualdades sociais. A cidade que crescia, convivia com a presença de meninos e meninas, em situação de abandono, que ocupavam as ruas e avenidas e faziam do espaço público local de trabalho e morada. A questão do abandono passou a ser propagada na imprensa local e nacional. Para o Diário de Pernambuco, o abandono tinha uma cor: sépia, que descoloria o cenário da cidade. Neste artigo, pretendo analisar como o discurso do abandono e as políticas públicas de assistência foram construídas nesse período sóciohistórico. A partir desse objetivo, proponho construir uma conexão com a atuação da Febem em Pernambuco, instituição fundada no primeiro ano da Ditadura Civil-Militar.

Palavras-chave: Menores Ambandonados - Recife; Fundação Estadual do Bem-Estar do Menor (PE); Menores de Rua.
Humberto da Silva Miranda

Doutor em História pela Universidade Federal de Pernambuco/UFPE. Professor da

Universidade Federal Rural de

Pernambuco/UFRPE. Grupo de Estudo e Pesquisa em História Social e Cultural/UFRPE Brasil

humbertosmiranda@yahoo.com.br

\section{Para citar este artigo:}

MIRANDA, Humberto da Silva. A cor do abandono: as crianças em situação de rua no Recife na ditadura civil-militar (1964-1985). Revista Tempo e Argumento, Florianópolis, v. 7, n.14, p. 155 - 179. jan./abr. 2015.

\section{DOI: $10.5965 / 2175180307142015155$}

http://dx.doi.org/10.5965/2175180307142015155 


\title{
The color of abandonment: the children living on the streets of Recife during the Civil-Military Dictatorship (1964-1985)
}

\begin{abstract}
The historiography records that the urban reality of Recife, during the Civil-Military Dictatorship (19641985), was marked by economic growth and increasing social inequality. The growing city had the presence of boys and girls occupying the streets and avenues that, in situations of abandonment, made the public space their workspace and habitation. The issue of abandonment began to repercute in local and national press. For the journal Diário de Pernambuco, the abandonment had a color: sepia, discoloring the city scenery. In this article, I pretend to analyze how the discourse of abandonment and public assistance policies were constructed in this sociohistorical period. With this purpose, I will trace a connection with the acting of FEBEM in Pernambuco, an institution founded in the first year of the Civil-Military Dictatorship.
\end{abstract}

Keywords: Abandoned. Children; FEBEM; Recife (PE).

Percorram-se os bairros do Recife, a qualquer hora do dia: por toda parte, magotes de meninos vadiando à toa, assaltando quintais, provocando barulho, ociosos e andejos, esmolando, dando tom de sépia à paisagem da cidade, quem são, em sua maioria? Meninos dos morros e dos córregos, dos mocambos e do "basfond" social, hoje simplesmente abandonados - porque sem pais ou sem lar que prenda e oriente, mais tarde, de certo, vocações de marginais, a matéria prima de que se sevem os batuques e as cadeias, quando não os cemitérios e as covas rasas. É 
que nos falta, a toda evidência, um programa sério de recuperação de menores, colégios, orfanatos, reformatórios, escolas artesanais, onde, recolhidos e educados, estes meninotes se pudessem transformar em elementos socialmente válidos e eugênicos. Na base de tudo, paira o problema econômico: "trapos humanos que perambulam, desocupados, pelas ruas". [...] Omissão do Estado, que prefere aturar este estado de causas sem uma providência cautelar, economizando aqui para, depois, gastar fortunas. ${ }^{1}$

A presença de crianças e adolescentes nas ruas do Recife revelava a fotografia de uma cidade descolorida, afirmava o editorial do jornal Diario de Pernambuco, publicado em fevereiro de 1966. De acordo com o periódico, a situação de abandono vivenciada por meninos e meninas dava o "tom sépia” à paisagem da metrópole, que "envelhecia” sem cuidar dos seus infantes.

A matéria possui um tom denunciador, acusando o Estado como o responsável pelo problema do abandono das crianças na cidade. Para o jornalista, os meninos abandonados se apropriavam das ruas, praticando as mais diversas ações que desafiavam a ordem estabelecida, provocando uma onda de insegurança nas pessoas que circulavam nos bairros da cidade.

Para o Diario, o “drama” do abandono, por marcar o cotidiano da cidade, exigia uma intervenção efetiva do Estado no dia a dia dessas crianças e adolescentes. De acordo com a matéria, os poderes estabelecidos estavam comprometidos em:

Espalhar abrigos que recolhessem essas sobras pelas comunidades, é menos oneroso, semear escolas artesanais, onde, aprendendo um ofício, dedicando-se a uma profissão, o menino, hoje moço e homem de amanhã, pudesse ser útil à coletividade, pagando, a juros tresdobrados, o que o Estado investiu na sua recuperação. ${ }^{2}$

O jornal assumia uma posição de legitimação das ações do governo estatal, reproduzindo os adjetivos depreciadores para identificar os meninos e as meninas de rua.

\footnotetext{
${ }^{1}$ DIARIO DE PERNAMBUCO. Editorial. O Drama do Menor Abandonado: editorial. Recife, 24 fev.,1966, p. 24

${ }^{2}$ Idem.
} 
Ao elaborar e publicar a matéria, o periódico registrava a sua concepção de abandono das crianças e adolescentes.

Nesse período, a imprensa da época, mais notadamente o já citado Diario, destacava, de forma sistemática, as ações do governo estadual no campo da assistência social, legitimando as suas práticas políticas e reproduzindo o discurso acerca da concepção sobre o abandono. Ao afirmar que cabia ao Estado o dever de tutelar as crianças abandonadas e as famílias pobres, o Diario legitimava o discurso do governo Paulo Guerra e dos setores da sociedade que concebiam a questão como um problema devido à "desestrutura familiar".

Em janeiro de 1966, publicava uma matéria intitulada Aumenta o número de pedidos de internamento de menores nos abrigos do Estado. De acordo com o documento:

O número de pedido de internamento de menores, através da Secretaria de Justiça, é elevado, chegando a atingir, este mês, uma média de 30 solicitações por dia, tendo sido encaminhadas, até ontem, 200 crianças ao Serviço de Assistência Social. O secretário João Roma informou que 30 mães de família o têm procurado quase diariamente; algumas chegam a pedir o internamento de dois filhos em virtude da precária situação financeira em que vivem ${ }^{3}$.

Ao se voltar para a cultura do abrigamento, a historiografia nacional tem contribuído no debate sobre a dinâmica de atendimento de instituições construídas no Brasil, destinadas à assistência de crianças em situação de abandono. De acordo com estudos da historiadora Maria Luísa Marcílio, os abrigos foram construídos, desde o período colonial, sob uma ótica caritativa e filantrópica para atender ao número expressivo de casos de abandono nos espaços urbanos, tendo a Igreja católica como articuladora das ações assistenciais. Segundo Marcicio (1967), no Brasil República, e mais notadamente nos anos 1960, a dinâmica do atendimento contou com uma maior

\footnotetext{
3 DIARIO DE PERNAMBUCO. Editorial. Aumenta o número de pedidos de internamento de menores nos abrigos do Estado. Recife, 6 jan. 1966, p. 12.
} 
Contudo, durante as pesquisas, encontrei a reportagem da Revista Realidade, que se posicionava de forma diferente em relação ao discurso do Diario de Pernambuco. Em 1967, a Realidade, que na época representava um dos maiores periódicos em circulação no País, dedicou uma extensa matéria sobre o problema do abandono no Recife, já então em nível nacional. Em perspectiva diferente da do jornal, a matéria da revista denunciava a falta de abrigo e como estavam sendo executadas as ações da Febem frente ao problema das crianças que viviam nas ruas da cidade:

Desde o princípio do ano, a Fundação do Bem-Estar do Menor fechou os abrigos do Estado aos meninos abandonados nas ruas do Recife, alegando que vai promover melhoramentos, alargar instalações, ampliar tais abrigos. Mas já estamos em junho e a situação continua a mesma, os abrigos não recebem mais ninguém. Dizem que no último encontro dos dirigentes da Fundação do Bem-Estar do Menor, para comer, beber, palestrar, passear, sorrir, foram gastos nada menos do que 50 milhões de cruzeiros velhos. Enquanto isso, os menores dormem pelas calçadas. Mas, para banquetes, há dinheiro 5 .

Esse trecho aponta a fragilidade do atendimento da Febem em função de suas deficiências. Os representantes da referida instituição são descritos como negligentes, sinalizando que a questão da assistência aos abandonados era também um problema de administração e de mau uso do recurso público.

A reportagem, intitulada Meninos do Recife, defendia a ideia de que o problema do abandono estava relacionado à questão econômica. Freire ainda argumentava que a solução estava na articulação entre o Estado e as organizações assistencialistas de caráter não-governamental. Nela encontramos a crítica ao sistema de abrigos, apontando que as instituições da cidade não suportavam a grande demanda. Freire afirmava que "[...] o

\footnotetext{
${ }^{4}$ MARCílIO, Maria Luiza. História Social da Criança Abandonada. São Paulo: Hucitec, 1989.

${ }^{5}$ FREIRE, Roberto. Os Meninos do Recife. Revista Realidade. Rio de Janeiro, ago. 1967, p. 31-32.
} 
Foi nesse cenário que Dom Helder, arcebispo de Olinda e Recife, publicou um texto que denunciava o cotidiano no abandono do Recife na década de 1970. O texto também criticava o sistema de atendimento promovido pela Febem. De acordo com o seu depoimento:

Conforme publica um dos nossos jornais, nós temos na Grande Recife 100 mil crianças abandonadas. E a FEBEM (Fundação Estadual de Bem-Estar do Menor) só tem meios de atender a 22 mil menores, em 22 núcleos e 8 colégios. Comentário: nenhum de nós pode lavar as mãos como Pilatos. Se estudarmos mais de perto o problema dos menores abandonados, veremos que se trata de uma consequência da situação de famílias em condição abaixo de humana, de desemprego, de miséria e de fome. Se todos nós nos unirmos para que em nosso país parem de projetos faraônicos, de preocupação econômica e supereconômica, sem a mais leve preocupação social; se todos nos unirmos para um basta a projetos com a pretensão de ser os maiores do mundo e exigirmos a atenção do Governo para os projetos de dimensão humana, veremos que é possível o que parece impossível. [...] Mas os agentes de Pastoral de nossa Arquidiocese registram um lado ainda mais doloroso. Dizem: "todos os bairros da Grande Recife têm as chamadas 'pequenas zonas', em plena prostituição". Isso é tremendo, sobretudo quando se sabe que a grande causa desta vergonha, desta chaga, é a miséria das famílias dos menores. É ou não o caso de cada bairro movimentar-se, verificar se a informação é válida para a sua área e unir esforços, salvar deste despenhadeiro estas pobres e queridas meninas-moças?

O discurso de Dom Helder se caracteriza por seu tom de denúncia e descortina um cenário de exclusão social. O "olhar" de d. Helder "sobre a cidade" sinaliza para as questões das desigualdades econômicas que marcam o cotidiano das famílias pobres. Sua fala sublinha a responsabilidade na superação de tais desigualdades, que atingiam mais diretamente os chamados "menores abandonados".

As matérias de jornais e o depoimento do religioso apontam para uma reflexão sobre a atuação da Febem. A instituição era uma instância estadual da Fundação Nacional do Bem-Estar do Menor (Funabem), criada no primeiro ano da Ditadura Civil-Militar,

\footnotetext{
${ }^{6}$ Idem.

${ }^{7}$ CÂMARA, Helder. Um olhar sobre a cidade: olhar atento, de esperança, de prece. São Paulo: Paulus, 1995.
} 
quando o então presidente Humberto de Alencar Castelo Branco promulgava a lei que estabelecia a Política Nacional do Bem-Estar do Menor (PNBEM), fazendo parte dessa política o sistema Funabem/Febem. Anos depois, em junho de 1966, o então governador de Pernambuco, Paulo Guerra, inaugurava sua instância local, a Fundação Estadual do Bem-Estar do Menor (Febem). Assim como em outros estados da Federação, a instituição responderia oficialmente, de acordo com a lei de sua criação, pelo atendimento a meninos e meninas que viviam em situação de "abandono", de "desvalia" e/ou de "delinquentes"8.

Até a criação da Funabem, o modelo de assistência em vigor no Brasil era o Serviço de Assistência a Menores $\left(\mathrm{SAM}^{9}\right)$, fundado no período do Estado Novo. De acordo com o Decreto/Lei $n^{\circ}$ 3.799, de 5 de novembro de 1941, o SAM foi criado para “[...] sistematizar e orientar os serviços de assistência a menores desvalidos e delinquentes, internados em estabelecimentos oficiais e particulares [...]", além de promover as políticas referentes aos menores em todo o território nacional ${ }^{10}$.

A Funabem, implantada em 1964 e extinta em 1990, passou mais de 20 anos procurando garantir a manutenção da Política Nacional do Bem-Estar do Menor, com medidas de disciplina e controle, pela qual estados e instituições particulares se subordinavam à sua administração centralizadora.

De acordo com o jornal, o governador Paulo Guerra já tinha enviado à Assembleia Legislativa o projeto de lei destinado à implantação de uma instituição voltada ao atendimento a meninos e meninas em situação de abandono, pobreza ou infração. De acordo com a reportagem, ao relatar a "exposição de motivos" para a criação da Febem, o governante afirmava:

A elaboração do projeto atende à necessidade de aplicar uma nova orientação ao grave problema da proteção ao menor, a exemplo do que ocorreu ao Governo Federal, que, tendo estudado o assunto sob todos os ângulos, houve por bem substituir o sistema superado de

\footnotetext{
${ }^{8}$ PERNAMBUCO, Diário Oficial. Lei N. 5810. Estabelece a criação da FEBEM. Recife, 14 de junho de 1966.

${ }^{9}$ Ainda não consta se foi construída uma História do SAM no Brasil e sua relação com Pernambuco. Aqui aponto a possibilidade de um trabalho sobre um tema ainda inexplorado. Sobre o SAM, ver: RIZZINI, Irene \& PILOTTI, Francisco. A arte de governar crianças: a história das políticas sociais, da legislação e da assistência à infância no Brasil. São Paulo: Cortez, 2009.

${ }^{10}$ BRASIL. Decreto-Lei 3.799, 5 nov. 1941. Estabelece a criação do Serviço de Assistência a Menores - SAM.
} 
administração, até então adotado, e que se mostrava inadequado e ineficiente. Acrescenta o Sr. Paulo Guerra que a "atual administração do Estado devotou interesse especial ao relevante problema, constituindo um dos objetivos prioritários do Governo o trabalho destinado a ampliar e melhorar os órgãos assistenciais de menores e procurando atrair a colaboração da comunidade, através de medidas especiais a cargo da Secretaria do Interior e Justiça". [...] No seu ofício, a Assembleia Legislativa, o Governador Paulo Guerra afirma que "não há a menor dúvida quanto à oportunidade, e mesmo à necessidade, da iniciativa, a que se reporta o referido projeto, sendo esta a maneira mais consentânea de manter e expandir a assistência ao "menor abandonado", que é uma das metas do Governo do Estado""11.

O tom de comemoração da matéria publicada pelo Diario de Pernambuco possibilita analisar que, para o periódico, a implantação da instituição no estado havia sido permeada por uma positividade que representava uma inovação no campo da assistência às crianças e adolescentes que viviam em situação de abandono. No decorrer das pesquisas, não foram encontrados documentos que registrassem os impactos da criação da Febem em Pernambuco; contudo, os veículos de comunicação de grande circulação local, afirmaram que sua construção "representava uma nova fase da assistência aos menores no Estado". De acordo com o Diario, competia à Febem:

Realizar estudos, inquéritos e pesquisas para desempenho da missão que Ihe cabe, promovendo cursos e seminários e procedendo ao levantamento, no território do Estado, do problema do menor; treinar pessoal técnico; articular-se com entidades públicas e privadas; opinar, quando solicitado pelo governador, secretários ou presidente da Assembleia Legislativa, em processos concernentes à concessão de subvenções; fiscalizar o cumprimento de contratos celebrados, assistir tecnicamente aos municípios que solicitarem; e mobilizar a opinião pública no sentido da indispensável participação de toda a comunidade na solução do problema do menor ${ }^{12}$.

A imprensa comemorava a "nova política do menor", que prometia resolver em pouco tempo os problemas dos meninos e meninas em situação de abandono, pobreza ou no mundo da delinquência. Anunciando que esta era mais uma ação da "Revolução de

\footnotetext{
${ }^{11}$ DIARIO DE PERNAMBUCO. Editorial. Criação da Febem atualizará a política do amparo ao menor. Recife, 16 abr. 1966.

${ }^{12}$ Idem.
} 
Março", reproduzia um discurso nacional. Os periódicos, mais notadamente o Jornal do Commercio e o Diario de Pernambuco, ainda afirmavam, em tom de festa, que Pernambuco seguia os passos dos generais. A Febem se apresentava como a "alternativa ideal" encontrada pelo Estado, “protetor" e “tutor", para resolver o "problema do menor”.

Ao analisar os documentos sobre a questão do abandono, observei que a instituição construiu um discurso próprio sobre a sua atuação diante do número crescente de crianças abandonadas no Brasil. A matéria intitulada De que um Estado precisa para atender o menor, publicada pela Revista Brasil Jovem, periódico da própria Funabem, noticiava como havia sido pactuada a burocracia para a execução dos projetos realizados nos estados:

Estabelecido o campo de atuação da Funabem, verificou a entidade a necessidade de criar uma infraestrutura, ao nível estadual, capaz de garantir o desenvolvimento de programas visando ao atendimento das necessidades básicas do menor: saúde, educação, recreação, amor e compreensão e segurança social. Para tanto, foram celebrados 72 convênios, desde 1966, com estados, territórios e Distrito Federal, proporcionando o Governo Federal assistência técnica e financeira direta no total de 18 milhões de cruzeiros, em todos os pontos do país. Para assegurar a expansão da Política Nacional do Bem-Estar do Menor, os estados são convidados pela Funabem a seguir diversas etapas para concretizar a infraestrutura local destinada ao atendimento social dos menores ${ }^{13}$.

Ao tratar das "etapas", a Funabem afirmava que, além de técnicos, espaço físico e equipamentos que os estados deveriam destinar à execução dos projetos financiados pelo governo federal, que buscava, por meio dessas medidas, atender aos governos estaduais, também identificados como "rede oficial”, e às instituições particulares.

O texto, intitulado Diretrizes e Normas para Aplicação da Política do Bem-Estar do Menor, permite-nos analisar como a sua missão institucional se distanciava da lógica dos direitos, haja vista que fazia uma opção voltada a crianças e adolescentes pobres pautada

\footnotetext{
${ }^{13}$ BRASIL. Fundação Nacional do Bem-Estar do Menor. In: Revista Brasil Jovem. Rio de Janeiro, a. V, $4^{\circ}$ trim. 1971.
} 
na perspectiva do assistencialismo. Ao definir seu campo de atuação, os idealizadores da Funabem afirmavam:

A Fundação Nacional do Bem-Estar do Menor assume, no entanto, como seu campo de trabalho, aquelas faixas populacionais que não são atingidas pelos esforços correntes de criação de condições de bem-estar, ou porque não se conta com recursos que permitam cobrir necessidades de todas as camadas populacionais, ou porque, por carências de ordem sócio-econômico-cultural, muitos grupos populacionais não têm possibilidades de se beneficiar das condições porventura postas à sua disposição ou de criar as condições de seu cargo. O campo de trabalho da Fundação se define, assim, como a faixa populacional cuja parcela de indivíduos de menor idade está sujeita a um processo de marginalização, entendendo-se por marginalização do menor, o seu afastamento progressivo, de um processo normal de desenvolvimento e promoção humana até a condição de abandono, exploração ou conduta antissocial ${ }^{14}$.

No período de vigência do projeto Febem/Funabem, de 1964 a 1989, a doutrina jurídica/assistencial se pautava pelo Código de Menores, que passou por uma alteração no ano de 1979. Nele, o abandono era concebido dentro da perspectiva da "Doutrina da Situação Irregular”. De acordo com os estudos de Isabel Frontana:

Ao redefinir a situação de abandono material e moral, o Código de Menores de 1979 considerava a expressão "situação irregular" a melhor forma de abranger aqueles estados de "marginalização" que caracterizavam o "menor", mantendo, no entanto, uma postura de diferenciação em relação a um destinatário considerado desajustado e não integrado, reiterando-se ainda que essas condições se devem à situação de irregularidade da própria família do "menor"”.

Para Frontana, o abandono era observado, pelos executores das políticas públicas, como uma "questão social". De acordo com seus estudos, a partir da década de 1970, os casos que envolviam os meninos e as meninas, muitas vezes "[...] rotulados como 'pivetes ou 'trombadinhas', eram vistos, por setores da sociedade brasileira, como um problema social. A presença dos garotos e garotas nas ruas era veementemente condenada, vista como motivadora de medo, insegurança, desordem e caos social [...]”.

\footnotetext{
${ }^{14}$ BRASIL, Fundação Nacional do Bem-Estar do Menor. Diretrizes e Normas para Aplicação da Política do BemEstar do Menor, 1966, p. 15.

${ }^{15}$ FRONTANA, Isabel. Crianças e Adolescentes: nas ruas de São Paulo. São Paulo: Edições Loyola, 1999. p. 67.
} 
Com o surgimento da Política Nacional do Bem-Estar do Menor (PNBEM), a questão do abandono obedecia, de forma mais sistematizada, às orientações do Poder Executivo. Para o historiador Gutemberg Rodrigues, a Funabem encarava a "questão do menor" como um problema de "Segurança Nacional", com implicações diretas na forma como o Estado lidaria com o problema do abandono no Brasil. De acordo com suas reflexões, a partir da criação da PNBEM, "o menor foi pensado como um dos objetivos nacionais permanentes", vinculando-se o abandono "à desagregação familiar, tendo como ponto de partida o êxodo rural e todas as vicissitudes impostas pela urbanização das grandes cidades" ${ }^{\prime 16}$.

Ao noticiar esse problema no Recife, no final da década de 1960, percebi que o Diario de Pernambuco agia como um "porta-voz" do governo Paulo Guerra, apresentando o problema a partir do viés da administração pública. Ao me debruçar sobre a Revista Realidade, constatei um posicionamento que contrariava as informações publicadas no Diario. Para a revista, o problema do abandono nesta cidade se devia também ao descaso dos governantes.

Ao analisar o trabalho da imprensa escrita, a historiadora Maria de Lourdes Janotti destaca a importância de perceber que o texto jornalístico "não se limita a uma simples constatação do vivido", cabendo ao historiador os “mecanismos de apreensão do real”, como “[...] ponto de vista do repórter-observador, a redação do noticiário, a edição do texto, editoração e arte, imagens do ângulo do fotógrafo, escolha das imagens, espaço disponível e posição política do jornal [... $]^{\text {"17 }}$.

Contudo, além da cultura institucional, que buscava abrigamento como solução para o abandono, percebi, no decorrer das leituras dessas matérias de jornais e nos documentos produzidos pela Febem/Funabem, uma campanha de que o abrigo seria a última decisão para os meninos e meninas. De acordo com Edson Passetti, no plano teórico, a Funabem buscou construir:

\footnotetext{
${ }^{16}$ RODRIGUES, Gutemberg Alexandrino. Os filhos do mundo: a face oculta da menoridade (1964-1979). 2000. Dissertação. Programa de Pós-Graduação em História. Universidade de São Paulo.

17 JANOTTI, Maria de Lourdes Monaco. Imprensa e ensino na Ditadura. In: FERREIRA, A. C.; BEZERRA, H. G. \& LUCA, T. R. de. O historiador e seu tempo. São Paulo: Editora da Unesp, 2008, p. 97.
} 
A nova proposta de atendimento ao menor estará ancorada na ideia de que Funabem, e suas correlatas nos demais estados brasileiros, não serão instituídas dentro de fundamentos paliativos, mas no de ser uma instituição diferente, onde o importante não será a internação. Ao contrário, vai proteger a criança na família, vai estimular obras que ajudem neste mister, vai ser auxiliar dos juízes de menores, vai cuidar da formação de pessoal especializado para o trato com os menores ${ }^{18}$.

Reforçando esta reflexão, no decorrer das pesquisas foram encontrados documentos produzidos pela instituição acerca da campanha da "manutenção do menor no lar". O discurso do relatório O bem-estar do menor identifica as funções de cada membro e sua importância na preservação de um "ideal” de família, tendo em vista a nova "realidade sociocultural da sociedade brasileira":

A manutenção do lar deixou de ser função primordial do chefe da família, tornando-se tarefa de todos os membros, incluindo mulheres e crianças. A baixa remuneração do pai, pela falta de qualificação profissional, exigiu a participação da mulher, com o trabalho fora do lar, para reforço do orçamento familiar. Essa participação da mulher nas responsabilidades financeiras libertou-a da tutela masculina, conferindo-lhe condições de igualdade ao homem e consequentemente autoridade nas decisões familiares. Ocorreu não só o seu afastamento dos afazeres domésticos, mas os cuidados aos filhos menores que são confiados à guarda mercenária de domésticas, à vigilância de vizinhos ou à guarda de irmãos um pouco mais velhos, quando não ficam entregues à própria sorte, na promiscuidade dos cortiços e das casas de cômodos (favelas, mocambos, malocas), ou na rua ${ }^{19}$.

A Funabem identificava os "papéis sociais" de pai, mãe, filhos, estendendo a responsabilidade também aos infantes. Esse discurso sinaliza que, para a instituição, a sociedade vivia no processo de intensas mudanças e que o lar deixava de ter as caraterísticas das famílias tradicionais, pelas quais o pai assumia a autoridade e o controle maior da "economia familiar" e a mãe respondia pelos afazeres domésticos, e os filhos, sempre obedientes, reproduziam os ditames das decisões dos adultos.

\footnotetext{
${ }^{18}$ PASSETTI, Edson. O menor no Brasil Republicano. In: DEL PRIORE, Mary. História da criança no Brasil. São Paulo: contexto, 1991, p. 151.

19 BRASIL, Fundação Nacional do Bem-Estar do Menor. Funabem. Aspectos da Política do Bem-Estar do Menor no Brasil. Rio de Janeiro, 1968, p. 20.
} 
Ao trazer à baila o problema do abandono, o editorial registrava que a saída era o recolhimento. Um lugar para abrigar as crianças que representavam uma ameaça social. Essa reportagem me fez lembrar o pensamento de Michel Foucault sobre a sociedade disciplinar, que buscou construir uma "economia do poder", estabelecendo dispositivos com os quais seria "mais eficaz e mais rentável vigiar que punir":

Todos conhecem as grandes transformações, os reajustes institucionais que implicaram as mudanças de regime político, a maneira pela qual as delegações de poder no ápice do sistema estatal foram modificadas. Mas, quando penso na mecânica do poder, penso em sua forma capilar de existir, no ponto que o poder encontra o nível dos indivíduos, atinge seus corpos, vem se inserir nos gestos, nas atitudes, seus discursos, sua aprendizagem, sua vida cotidiana ${ }^{20}$

É possível afirmar que a Funabem buscava atuar de forma capilar, procurando construir outra "mecânica de poder". Além dos abrigos, era necessário atuar de forma mais direta nas famílias, com uma ação mais efetiva no controle sobre o cotidiano dos grupos populares, haja vista que o aumento de pedido de internação vinha desse público. Foi nesse cenário que modelou outros exercícios de poder, procurando construir “instrumentos de transformação dos indivíduos”, de forma microscópica e capilar.

Para a Funabem, a família representava o "principal grupo transmissor de cultura"; daí a importância do Estado em controlar o seu cotidiano. Para a instituição, a disfunção se devia a diversos fatores: "insuficiência na oferta de novos empregos", "instabilidade do mercado de trabalho nas zonas urbanas e rurais" e "conflito entre a concepção tradicional de família". Sua preocupação, exposta nos documentos, era com os novos arranjos familiares, tendo em vista a falência do modelo de família patriarcal e a crise da família nuclear burguesa. Os relatórios já indicavam que muitas das famílias que procuravam seus serviços eram chefiadas por mulheres, grupos que não contavam com a presença masculina do pai.

O discurso da função da família construído pela Funabem vinha acompanhado da ideia de “disfunção”, ou seja, de famílias que, devido à condição de pobreza ou de outras

\footnotetext{
${ }^{20}$ FOUCAULT, Michel. Microfísica do Poder. Rio de Janeiro: Graal, 2007, p. 130-131.
} 
Por consequência, as disfunções do grupo familiar implicam o comprometimento do processo de socialização, em graus diversos. A família contemporânea exibe um complexo quadro de deficiências, cujas causas podem ser encontradas, em parte, nos problemas gerais da sociedade ${ }^{21}$.

Percebo nessa concepção um modelo de família relacionado ao conceito tradicional, ao "modelo ideal”, nuclear, em que o pai, a mãe e os filhos tinham papéis definidos. Para a instituição, a família era um grupo responsável pela "sociabilização" das novas gerações e pela transmissão da cultura. Este conceito defendia a família tradicional, criticando a chamada "família contemporânea", formada por grupos de mães solteiras, ou seja, famílias chefiadas por mulheres.

Esse discurso lembra o que a historiadora Michelle Perrot fala do ideário burguês acerca da relação entre família e Estado, quando afirma:

A família, átomo da sociedade civil, é a responsável pelo gerenciamento dos "interesses privados", cujo bom andamento é fundamental para o vigor dos Estados e o progresso da humanidade. Cabe-lhe um número de funções. Elemento essencial da produção, ela assegura o funcionamento econômico e a transmissão dos patrimônios. Como célula reprodutora, ela produz as crianças e proporciona-lhes uma primeira forma de socialização (PERROT, 2009, p. 91).

Segundo a autora, para a lógica burguesa, a "boa família é o fundamento do Estado"; daí seu interesse por sua manutenção, principalmente das famílias pobres, que representam o "elo fraco do sistema”. Para a historiadora francesa, as funções da família estão intimamente relacionadas às questões políticas e econômicas do Estado moderno.

\footnotetext{
${ }^{21}$ BRASIL, Fundação Nacional do Bem-Estar do Menor. Funabem. Aspectos da Política do Bem-Estar do Menor no Brasil. Rio de Janeiro, 1968, p. 115.
} 
A partir dessa reflexão, podemos analisar de forma mais efetiva o discurso e as medidas de prevenção e combate ao abandono confiadas à Funabem.

Os relatórios registram a preocupação da instituição com os casos de abandono sob a justificativa da pobreza. O documento Aspectos da Política do Bem-Estar do Menor no Brasil afirma que nem sempre a situação de pobreza resulta no abandono ou na internação, estabelecendo recomendações no sentido de reafirmar a "necessidade de desenvolver sempre a política de fortalecimento do núcleo familiar e a busca permanente de sua consolidação como medida preventiva da marginalização do menor"222:

A internação poderá ser uma derivada de complicações financeiras ao nível do grupo familial, impedindo de adquirir serviços de educação e de financiar as necessidades básicas de alimentação, vestuário e saúde, mas, que, compelida a atendê-las, exerce pressão para o internamento do menor $^{23}$.

Para a Funabem, além do fator econômico, o problema do êxodo rural, da ocupação da mulher no mundo do trabalho e as outras formas de "patologias sociais", como a "embriaguez" e a "prostituição", eram responsáveis pelo comprometimento do "automatismo" do grupo familial, com repercussão direta sobre o aumento dos casos de internação e abandono. Recomendava que as fundações estaduais optassem pelo fortalecimento das famílias e procurassem a internação como última instância:

A problemática do menor compõe-se, em essência, da demanda de serviços substitutivos das funções familiares exercidas junto às associações assistenciais. Surge quando os serviços extra-familiares, em qualquer de suas formas, passam a ser consideradas como a melhor alternativa, quer solicitada pelos responsáveis, quer imposta pela autoridade judiciária. A situação-limite, centro de nossas negociações, é o internamento ${ }^{24}$.

\footnotetext{
22 BRASIL. Fundação Nacional do Bem-Estar do Menor. Brasil Jovem - Revista da Fundação Nacional do Bem-Estar do Menor, n. 30, a. VIII. Rio de Janeiro: Funabem, 1974, p. 7.

${ }^{23}$ Este documento objetivou publicar o resultado das discussões do I Encontro Sul-Americano do Bem-Estar do Menor, ocorrido no Rio de Janeiro no final dos anos 1960. BRASIL, Fundação Nacional do Bem-Estar do Menor. Funabem. Aspectos da Política do Bem-Estar do Menor no Brasil. Rio de Janeiro, 1968, p. 115.

${ }^{24}$ Ibidem, p. 110.
} 
Constatei que concepção de família pobre estava correlacionada à preocupação com a função da instituição e seus membros junto à sociedade. Para a instituição, tais funções deviam ser exercidas em conjunto com as associações assistenciais, sendo tal relação legitimada pela “autoridade judiciária”. Este discurso visava a legitimar toda a atuação junto a essas famílias, uma vez que os mecanismos de intervenção tinham por objetivo controlar o seu cotidiano.

A crescente demanda por assistência social se desdobrou na construção de estratégias políticas por parte da gestão estadual:

Face às deficiências nos atuais abrigos, o Governador Paulo Guerra determinou ao Serviço de Assistência que efetue rigorosa pesquisa junto às famílias, através das assistentes sociais, nas próprias residências, a fim de observar as reais condições das requerentes. [...] Após esse trabalho, o Juizado de Menores procede a uma completa triagem, aproveitando nas vagas existentes nos diversos abrigos aqueles meninos cujos pais, por extrema necessidade, não dispõem de condições suficientes para mantê-los. No caso de ser constatada a possibilidade de o menor ser assistido pela própria família, o juiz entrega-o aos seus pais ${ }^{25}$.

Através da leitura desse trecho, é possível afirmar como foi construída a rede de atendimento aos casos de abandono do Recife. Compunham esse cenário o sistema de assistência social e o Poder Judiciário, que, de acordo com o texto, se articularam no sentido de melhor enfrentar as deficiências dos abrigos. Como saída, a matéria afirmava que o Estado se comprometia a construir novas unidades de internamento e a realizar um trabalho de combate às práticas de abandono no Recife, contando com o apoio do juizado.

De acordo com a matéria, as famílias pobres concebiam o Estado como tutor da sociedade, responsável pela criação dos seus filhos. O Estado, por sua vez, procurava responder intervindo no cotidiano dessas famílias, apontando, inclusive, como uma das soluções do problema, a ampliação do número de vagas nos abrigos e procedimentos técnicos de intervenção direta no cotidiano dessas famílias populares.

\footnotetext{
${ }^{25}$ Ibidem.
} 
A análise do discurso do Diario de Pernambuco permite conceber a relação do Estado com o problema do abandono de crianças. De acordo com estudos de Irma e Irene Rizzini, a relação entre a cultura política de assistência às crianças e adolescentes pertencentes às famílias populares pode ser entendida com o próprio surgimento da categoria jurídica do "menor abandonado", que passou a definir um conjunto de procedimentos legais e a estabelecer políticas de atendimento baseadas no discurso, tanto da "ausência dos pais, quanto na incapacidade da família de oferecer condições apropriadas de vida à sua prole", fazendo com que o Estado assumisse o cotidiano dessas crianças e suas famílias ${ }^{26}$.

Ao se voltar às práticas de controle social sobre as famílias, Jacques Donzelot afirma que o Estado moderno buscou criar mecanismos de controle demográfico e político sobre a população, interferindo diretamente na educação dos filhos das famílias pobres, valendo-se do conceito de prevenção social. De acordo com o autor, tal estratégia buscava fortalecer a própria ideia de família como grupo homogêneo, reprodutor dos interesses do Estado $^{27}$.

É importante registrar que, para entender a atuação da Febem, é de fundamental importância construir uma conexão com o chamado "Sistema de Justiça", que, no período em foco, atuava sob a égide do Código de Menores. O sociólogo Edson Passetti afirma que, no século XX, "o Estado assume o lugar da igreja como centro da caridade, procurando ofuscar, com sua racionalidade, uma experiência de milênios". A partir dessa perspectiva, o Estado se apoiou no sistema jurídico, materializado no Código de Menores de 1927:

O instrumento jurídico balizador desta continuidade foi, em primeiro lugar, o Código de Menores de 1927, que procurava não só regulamentar o trabalho de crianças e adolescentes, mas também definir a emergência do "menor perigoso" como decorrente da situação de pobreza. O Código de Menores de 1979 reviu essa perspectiva a partir da concepção de situação irregular como origem do delinquente ${ }^{28}$.

\footnotetext{
${ }^{26}$ RIZZINI, Irene; RIZZINI, Irma. A institucionalização de crianças no Brasil. Rio de Janeiro: Loyola, 2004, p. 29.

${ }^{27}$ DONZELOT, Jacques. A polícia das famílias. Rio de Janeiro: Graal, 2001.

${ }^{28}$ PASSETTI, Edson. Violentados: crianças, adolescentes e justiça. São Paulo: Editora Imaginário, 1999, p. 25
} 
Através dessa burocracia, a Funabem estabelecia um contrato com os estados, buscando controlar as ações desenvolvidas nas unidades chamadas febems. Ainda de acordo com Passetti:

Em nome do bem, o Estado acaba realizando o bem-estar da própria burocracia, fazendo recair a ênfase no grau maior ou menor de corrupção. O que perpetua é a possibilidade - por vias mais ou menos obscuras - de realizar, primordialmente, o bem-estar da própria categoria, como em toda corporação ${ }^{29}$.

No período republicano, o atendimento às crianças abandonadas nos abrigos sofria um maior controle do Juizado de Menores, que, por sua vez, tinha como referência o Código de Menores, promulgado em 1927 e reformulado em 1979. De acordo com o trabalho da historiadora Sônia Camara, o código passou a determinar que:

O abrigo de menores deveria funcionar como órgão intermediário, encarregado de promover a guarda temporária e a observação dos "menores". Nele seria indicada a profilaxia necessária para o tratamento, até que fossem prescritas as medidas concernentes à colocação definitiva do "menor" em instituições de regeneração, de preservação ou qualquer outra recomendação. Com base no Código, o abrigo compunhase de duas divisões: uma masculina e outra feminina, subdivididas em seções destinadas aos abandonados e delinquentes, distintamente. ${ }^{30}$

Seus estudos ainda registram que esse processo de normatização dos abrigos foi inspirado na lógica do "identificar e classificar para educar e regenerar”. O código estabelecia uma série de normativas para os abrigos, para os institutos disciplinares e para os conselhos de assistência e proteção, tendo o Juizado de Menores como o órgão regulador e fiscalizador da estrutura e funcionamento desses espaços assistenciais.

Os trabalhos historiográficos sinalizam que o Brasil República demarcou uma nova fase na história do abandono. De acordo com os estudos de Silvia Arend:

O Código de Menores de 1927 é considerado um marco no que tange à legislação infanto-juvenil. Esse ordenamento contempla as discussões

\footnotetext{
${ }^{29}$ Ibidem, p. 56.

${ }^{30}$ CAMARA, Sonia. Sob a guarda da República: infância e menoridade no Rio de Janeiro da década de 1920. Rio de janeiro: Quartet, 2010, p. 264
} 
que vinham sendo realizadas em nível internacional, sobretudo nos Congressos Pan-americanos da Criança, e na sociedade brasileira nas primeiras décadas do século XX. Segundo esses discursos, formulados pelas elites sob a ótica dos ideários do progresso e da civilização, era preciso "salvar" as crianças e os jovens pobres do Brasil do abandono, do ócio e do vício. É importante observar que, a partir da instituição da primeira legislação menorista, o Poder judiciário torna-se uma peça fundamental na administração da assistência ${ }^{31}$.

Suas reflexões permitem analisar o lugar do Juizado de Menores na construção do conceito de abandono e na construção das políticas públicas elaboradas no campo da assistência às crianças de rua. Nesse trecho, a promulgação do Código de Menores, em 1927, foi considerada pelos historiadores contemporâneos como um marco na trajetória da assistência à infância no País, uma legislação exclusiva que norteava as ações da justiça e da assistência aos meninos e às meninas que viviam em situação de abandono.

A historiadora Elaine Maria Bueno Bernal, em seu trabalho Arquivos do Abandono afirma que as concepções de abandono produzidas no século XX "refletiam também as projeções futuras dos juristas, que ora estabeleciam a infância como promessa do futuro do País, ora se encarregavam de alertar para o limite ínfimo entre a infância promissora e delinquente":

Para aquele sistema jurídico-institucional, "ser abandonado" era tão abrangente quanto complexo. No período, identificou-se uma intricada construção histórica do conceito de abandono, tanto de infância quanto de adolescência. Com relação às crianças e jovens internados pelo Serviço Social de Menores, o processo de julgamento do abandono se dava a partir do momento em que a criança era tida como em situação de risco, o que significava estar em condições consideradas impróprias para o seu desenvolvimento físico, emocional e moral, ou se considerasse que as condições em que era criada eram impróprias, comprometendo sua formação como cidadão capaz de trabalhar e contribuir para o progresso da cidade e de toda a nação. O processo de julgamento do abandono era composto de várias etapas, que iam desde a investigação da vida das crianças e jovens pelos comissários de vigilância até a sentença final do juiz de menores..$^{32}$.

\footnotetext{
${ }^{31}$ AREND, Silvia. De exposto a abandonado: uma trajetória jurídico-social. VENÂNCIO, Renato. In: Uma história social do abandono de crianças: de Portugal ao Brasil (séculos XVIII-XX). São Paulo: Alameda, 2010, p. 353.

32 BERNAL, Elaine. Arquivos do Abandono. São Paulo: Cortez, 2004, p. 43.
} 
Bernal afirma ainda que, a partir desse instrumento jurídico-normativo, o Brasil passou a ter uma legislação exclusiva, a qual, por sua vez, estabelecia categorias e critérios de abandono:

Podemos verificar que, na prática da Justiça, o critério de abandono adotado pelo Código de Menores resultou em amplas interpretações sobre o assunto. As crianças e jovens seriam alvo dessa assistência repressora em várias situações encontradas em suas vidas, e muitas delas, internadas pelo Serviço Social de Menores como abandonadas, eram, em sua grande maioria, crianças pobres com modos de vida diferentes daqueles considerados adequados pelas concepções dominantes ${ }^{33}$.

No período de vigência do projeto Febem/Funabem, de 1964 a 1989, a doutrina jurídica/assistencial se pautava pelo Código de Menores, alterado no ano de 1979. Nessa alteração, o abandono era visto da perspectiva da "Doutrina da Situação Irregular". De acordo com os estudos de Isabel Frontana:

Ao redefinir a situação de abandono material e moral, o Código de Menores de 1979 considerava a expressão "situação irregular" a melhor forma de abranger aqueles estados de "marginalização" que caracterizavam o "menor", mantendo, no entanto, uma postura de diferenciação em relação a um destinatário considerado desajustado e não integrado, reiterando-se ainda que essas condições se devem à situação de irregularidade da própria família do "menor"34.

Ressalta, ainda, o trabalho da historiadora que o abandono era encarado pelos executores das políticas públicas como uma "questão social". De acordo com seus estudos, da década de 1970 em diante, os casos que envolviam meninos e meninas, muitas vezes “[...] rotulados como 'pivetes ou 'trombadinhas', passaram a ser vistos, por setores da sociedade brasileira, como um problema social. A presença dos garotos e garotas nas ruas era veementemente condenada, vista como motivadora de medo, insegurança, desordem e caos social [...]"35.

Com a criação da Febem e a manutenção do Código de Menores, a expressão menor, que já fazia parte do cotidiano do sistema jurídico, ocuparia com mais intensidade,

\footnotetext{
33 Idem, p. 51.

${ }^{34}$ FRONTANA, Isabel. Crianças e Adolescentes: nas ruas de São Paulo. São Paulo: Edições Loyola, 1999, p. 56.

35 Ibid., p. 67.
} 

perigosos ou postos em perigo" -, mas também de práticas de intervenção do judiciário e social" ${ }^{36}$.

Percebo que os discursos construídos sobre os chamados menores e as políticas públicas buscavam montar um projeto de defesa social, no qual o Código de Menores representasse a materialização do campo jurídico e servisse de base também às políticas sociais. Segundo Brito, o código foi elaborado a partir da perspectiva da criminologia fundada na Escola Positiva de Direito Penal, que, historicamente, enveredou pelo campo social, buscando defender a sociedade pelo viés da prevenção ${ }^{37}$.

Com o surgimento da Política Nacional do Bem-Estar do Menor (PNBEM), a questão do abandono se subordinou de forma mais sistematizada ao Poder Executivo. Para o historiador Gutemberg Rodrigues, a Funabem encara a "questão do menor" como um problema de "Segurança Nacional", influindo diretamente na forma como o Estado deveria lidar com o problema do abandono no Brasil, conforme exposto na argumentação que o levou a criar a PNBEM ${ }^{38}$.

É nesse cenário social que aparecem os "meninos do Recife". O artista pernambucano Abelardo da Hora, editado no início dos anos de 1960 pelo Movimento de Cultura Popular, ao descrever as cenas dos meninos dessa cidade, que, com o crescimento, reproduzia imagens e representações de crianças e adolescentes transitando nas ruas e avenidas da capital, poetizou seu cotidiano de forma marcante:

Meninos do Recife

São habitantes anônimos dessa cidade alagada, de limo e pedra formada sob marés submersa. Em lodo em lama inconsistente, consubstanciada. Vasto poço de afogados, habitação de mitos e fantasmas. Imenso pasto de peste. Cidade desabrigada. Habitantes desse pântano, sem escrituras,

\footnotetext{
${ }^{36}$ BRITO, Eleonora. Justiça e Gênero: uma história da Justiça de menores em Brasília (1960-1990). Brasília: Editora da Universidade de Brasília, 2007. P. 115

${ }^{37}$ Idem.

${ }^{38}$ Cf. p. 9.
} 
sem títulos, submetidos ao ócio que gera a fome e o vício e um calendário implacável de misérias e imprevistos. São habitantes dessa cidade alagada. Atirados sobre a mala, Sob as marés da desgraça. ${ }^{39}$

O poema constrói cenas de um cotidiano de fome e miséria, ou seja, de desigualdade social. Os protagonistas, os meninos, são "anônimos", mas visíveis no cenário de uma cidade alagada, pantanosa, que não acolhe e desabriga nossas crianças e adolescentes. Uma cidade que não acolhe, mas abandona.

\section{Considerações Finais}

O poema de Abelardo, o texto de Dom Helder e as matérias de jornais publicadas no período da Ditadura Civil-Militar registram como foi construído o cotidiano do abandono no Recife: período marcado por intensas transformações sociais, quando o Estado procurou tutelar as crianças que viviam em situação de abandono, buscando controlar o cotidiano das famílias pobres.

Naquele período, o conceito de abandono foi construído sob uma lógica assistencialista. O Estado, para elaborar políticas de atendimento, se guiou pelo Código de Menores, uma legislação que, por sua vez, reproduzia o princípio do controle e vigilância sobre aqueles que representavam uma ameaça para o progresso e a segurança. A atuação da Febem, em Pernambuco, foi construída com tal justificativa. A instituição buscou atuar de acordo com os ditames da Política Nacional do Bem-Estar do Menor, estabelecida no primeiro ano da Ditadura Civil-Militar.

Mas como foi construída a imagem dos abandonados? Dos meninos e das meninas que viviam as mais diferentes situações de exclusão social? Ao descortinar o abandono no Recife, o editorial do Diario de Pernambuco, em 1966, estabelecia formas de classificação dos garotos e das garotas, identificando-os como "vadios", "trapos humanos" e “sobras". Tais classificações, como observamos pela leitura dos documentos, também permeavam o conceito de abandono assumido pela Febem e pelo Sistema de Justiça.

\footnotetext{
${ }^{39}$ HORA, Aberlardo. Meninos do Recife. Livreto Movimento de Cultura Popular - MCP. Recife, 1964.
} 
Abandono de cor sépia, como registrou o editorial do Diário de Pernambuco. Cor que envelhecia a cidade e a tornava descolorida.

\section{Referências}

Aumenta o número de pedidos de internamento de menores nos abrigos do Estado. Diário de Pernambuco, Recife, 6 jan., 1966, p. 12.

AREND, Silvia. De exposto a abandonado: uma trajetória jurídico-social. In: VENÂNCIO, Renato. Uma história social do abandono de crianças: de Portugal ao Brasil (séculos XVIII-XX). São Paulo: Alameda, 2010, p. 339-359.

BERNAL, Elaine. Arquivos do abandono. São Paulo: Cortez, 2004.

BRASIL. Decreto-Lei 3.799, de 5 de novembro de 1941. Transforma o Instituto Sete de Setembro, em Serviço de Assistência a Menores e dá outras providências. Brasília: Camara dos deputados, 1941. Disponivel em: <http://www2.camara.leg.br/legin/fed/ declei/1940-1949/decreto-lei-3799-5-novembro-1941-413971-publicacaooriginal-1-pe.html>. Acesso em 12 de fev. 2105.

BRASIL. Fundação Nacional do Bem-Estar do Menor. Diretrizes e normas para aplicação da política do bem-estar do menor, 1966.

BRASIL. Fundação Nacional do Bem-Estar do Menor. Aspectos da política do bem-estar do menor no Brasil. Rio de Janeiro, 1968.

BRASIL. Fundação Nacional do Bem-Estar do Menor. Revista Brasil Jovem. Rio de Janeiro, Ano V, $4^{\circ}$ trim., 1971.

BRASIL. Fundação Nacional do Bem-Estar do Menor. Revista Brasil Jovem -n. 30, a. VIII. Rio de Janeiro: Funabem, 1974.

BRITO, Eleonora. Justiça e gênero: uma história da justiça de menores em Brasília (19601990). Brasília: Editora da Universidade de Brasília, 2007, p. 115.

CÂMARA, Helder. Um olhar sobre a cidade: olhar atento, de esperança, de prece. São Paulo: Paulus, 1995.

CAMARA, Sonia. Sob a guarda da república: infância e menoridade no Rio de Janeiro da década de 1920. Rio de janeiro: Quartet, 2010. 
Criação da Febem atualizará a política do amparo ao menor: editotorial. Diário de Pernambuco, Recife, 16 de abr., 1966.

DONZELOT, Jacques. A polícia das famílias. Rio de Janeiro: Graal, 2001.

O Drama do Menor Abandonado: editorial. Diário de Pernambuco, Recife, 24 fev.,1966, p. 24.

FOUCAULT, Michel. Microfísica do poder. Rio de Janeiro: Graal, 2007.

FREIRE, Roberto. Os Meninos do Recife. Revista Realidade. Rio de Janeiro, n.00, p.00-00, agosto, 1967.

FRONTANA, Isabel. Crianças e Adolescentes: nas ruas de São Paulo. São Paulo: Edições Loyola, 1999.

HORA, Aberlardo. Meninos do Recife. Livreto Movimento de Cultura Popular - MCP. Recife: MCP, 1964.

JANOTTI, Maria de Lourdes Monaco. Imprensa e ensino na Ditadura. In: FERREIRA, Antonio Celso; BEZERRA, Holien Gonçalves;LUCA, Tania Rregina de. O historiador e seu tempo. São Paulo: Editora da Unesp, 2008.

MARCÍLIO, Maria Luiza. História social da criança abandonada. São Paulo: Hucitec, 1989.

PASSETTI, Edson. O menor no Brasil Republicano. In: DEL PRIORE, Mary. História das crianças no Brasil. São Paulo: contexto, 1991.

PASSETTI, Edson. Violentados: crianças, adolescentes e justiça. São Paulo: Editora Imaginário, 1999.

PERROT, Michelle. Funções da família. In: PERROT, Michelle (Org.). História da vida provada (4): da revolução francesa à primeira guerra. São Paulo: Companhia das Letras, 2009.

PERNAMBUCO. Lei N. 5810. Estabelece a criação da FEBEM. Diário Oficial de Pernambuco, Recife, 14 de junho de 1966.

RIZZINI, Irene; RIZZINI, Irma. A institucionalização de crianças no Brasil. Rio de Janeiro: Loyola, 2004. 
RIZZINI, Irene; PILOTTI, Francisco. A arte de governar crianças: a história das políticas sociais, da legislação e da assistência à infância no Brasil. São Paulo: Cortez, 2009.

RODRIGUES, Gutemberg Alexandrino. Os filhos do mundo: a face oculta da menoridade (1964 - 1979). 2000. Dissertação (Mestrado em História) - Universidade de São Paulo, Programa de Pós-Graduação em História. São Paulo, 2000 